\title{
IJMWT Special Issue on the 2013 National Microwave Days in France
}

\author{
MARTINE VILlEGAS ${ }^{1}$, JEAN-LUC POLLEUX ${ }^{1}$ AND XAVIER BEGAUD ${ }^{2}$
}

This special issue of the International Journal of Microwave and Wireless Technologies is dedicated to topics discussed during the 18th Bi-annual French National Microwave Days (18th JNM), held in Paris, France, on May 15-17, 2013. The 18 th JNM conference was held at "la Cité des Sciences" in Paris, France, and organized by ESYCOM (ESIEE Paris, Université Paris-Est Marne-la-Vallée, Le Cnam) and a panel of industrials and university from Ile-de-France: THALES, III-V lab, ORANGE, Onera, Telecom Paris Tech, ETIS, LSS-SUPELEC, L2E-UPMC.

This very successful event welcomed more than 550 conference attendees, both from France and abroad, in Northeast Paris, within the Parc de la Villette cultural and leisure complex. The Cité des Sciences is ideally situated to welcome a wide range of visitors, many of whom may be unused to frequenting cultural institutions.

The technical program, through oral and poster sessions, focused on the following topics: "Antennas and Propagation", "Passive Components", "Active Components", "Systems and associated processing", and "Emerging technologies and functional materials". The 18th JNM congress was preceded by a 1-day special topic conference on "Communication systems for the city, the environment and the person" organized by ESYCOM at Cité Descartes in Marne La Vallée.

The scientific committee of the 18 th JNM was chaired by Professor Christian Person (Lab-STICC, Brest) with the vice president, Professor Martine Villegas (ESYCOM).

A total of 323 papers of a high technical level were presented: 156 papers were presented during 34 oral sessions, and 167 posters were presented in 11 poster sessions. An exhibition space was also dedicated to exhibitors during the 3 days. The local organizing committee, with a team of many enthusiastic volunteers, was chaired by Professor Martine Villegas and co-chaired by Associate Professor Jean-Luc Polleux. The scientific organization was conducted by Professor Martine Villegas, Professor Xavier Begaud and Associate Professor Antoine Diet.

The 18th JNM event was also supported by the European Microwave Association (EuMA), the Institute of Electrical and Electronics Engineers (IEEE), and the Groupement De

\footnotetext{
${ }^{1}$ Université Paris-Est, ESYCOM, ESIEE-Paris, UPEM, Le Cnam - Cité Descartes, BP 99, 93162 Noisy-le-Grand, France.

${ }^{2}$ Institut Mines-Télécom, Télécom ParisTech - LTCI CNRS UMR 5141 - 46 rue Barrault 75634, Paris cedex 13, France.

Corresponding author:

M. Villegas

Email: martine.villegas@esiee.fr
}

Recherche from the National Center for Scientific Research (GDR Ondes, CNRS) and three special prizes were awarded for best papers. The recipients of the IEEE Best paper award are Václav Valenta, Andreas Trasser, Hermann Schumacher, Mehmet Kaynak for their paper entitled "Quadrupleur de fréquences en technologie SiGe:C BiCMOS $130 \mathrm{~nm}$ pour un radar à ondes continues modulées en bande-F”. The recipients of the EuMA Best student paper award are Burdin François, Podevin Florence, Ferrari Philippe for their paper entitled "Diviseur de puissance flexible et miniaturisé". The recipients of the EuMA Best student poster award are Niemiec Ronan, Bennis Anass, Brousseau Christian, Mahdjoubi Kouroch, Emile Olivier for their paper entitled "Excitation du moment angulaire orbital (OAM) d'une onde en bande millimétrique, à partir d'une lame de phase".

This special issue of the International Journal of Microwave and Wireless Technologies, published by Cambridge University Press in collaboration with EuMA, covers the five topics with papers selected from the 30 best papers presented at the 18 th JNM Conference. The authors were requested to submit their papers, 16 submitted their contributions and 32 international reviewers agreed to review the English versions. Finally, eight of those papers were found suitable for publication in this special issue and five of those papers will be published in a next issue. We wish to acknowledge all the authors for submitting their papers and all the reviewers for the in-depth evaluation of them and revised versions from July to December 2013. We hope that this special issue will be enjoyable and of interest to the readers through the various topics in the microwave field, and also that they will find extensive and useful information for their own research activities.

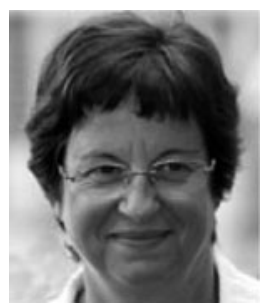

Martine Villegas graduated from the "Ecole Nationale Supérieure de l'Electronique et des Applications" (ENSEA), Paris, France, in 1981. In 2007, she received the qualification as Ph.D. Supervisor (HDR), from the University of Marne-la-Vallée.

After an experience of some years in the industry as designer of microwave monolithic integrated circuits, she joined the world of education and research and ESIEE-Paris. She developed the activities in the area of the circuits and systems in radio-frequency and microwaves fields, then in the digital radio communications. She is currently Professor at ESIEE Paris in the Telecommunications Department and the ESYCOM laboratory. 


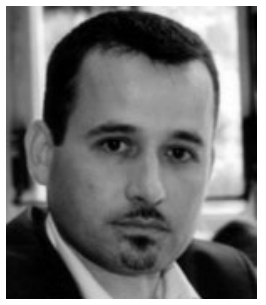

Jean-Luc Polleux received a Master degree/Diplôme d'ingénieur in microelectronic from ENSEIRB, Bordeaux, France, and the DEA degree in electronic and telecommunications from the University of Bordeaux 1, France, both in 1997. He received the Ph.D. degree in the opto-microwave field from CNAM, Paris, in 2001. He then joined ESIEEParis at Université Paris-Est (UPE), France, and the joint laboratory ESYCOM. He is now associate professor. His current research involves microwave-photonics devices and systems for Radio-over-Fibre applications with special emphasis on microwave phototransistors ( $\mathrm{SiGe} / \mathrm{Si}$ and $\mathrm{InGaAs} / \mathrm{InP}$ ), silicon-based integration and opto-microwave devices modeling. He published over 60 journal papers, patents, and conference articles. $\mathrm{He}$ is administrator of Optics'Valley, Ile-de-France region, and head of the international master of Electronics, Wireless communications, Micro-Nano-Technologies of ESIEE Paris UPE. He co-organized three international workshops and cochaired the local committee of JNM2013.

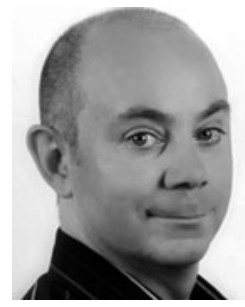

Xavier Begaud received a M.S. degree in optics, optoelectronics, and microwaves, from Institut National Polytechnique de Grenoble (INPG) in 1992. He received the Ph.D. degree from the University of Rennes in 1996 and the habilitation degree from Pierre and Marie Curie University (Paris 6) in 2007. He joined the Télécom ParisTech (formerly Ecole Nationale des Telecommunications) in 1998, where he is currently Professor and Head of the RF and Microwave group (RFM) at COMmunications and ELECtronics Department (COMELEC). His research topics include theory, conception, modeling, and characterization of wideband, bipolarized, and $3 \mathrm{D}$ antennas with special emphasis on numerical methods. Currently, research activities include design of metamaterials, channel sounding, and mutual coupling analysis in the framework of ultra-wideband and software radio. He has published over 160 journal papers, patents, book chapters, and conference articles. He has organized two international conferences as the general chairman and edited one book. 